\title{
Mariona VERNET et Eulalia VERNET (éd. et trad.), Ordo Virtutum: Hildegarda de Bingen
}

Éric Palazzo

\section{OpenEdition}

\section{Journals}

Édition électronique

URL : https://journals.openedition.org/ccm/5435

DOI : $10.4000 / \mathrm{ccm} .5435$

ISSN : 2119-1026

\section{Éditeur}

Centre d'études supérieures de civilisation médiévale/Université de Poitiers

\section{Édition imprimée}

Date de publication : 1 décembre 2020

Pagination : 309-310

ISBN : 978-2-490783-07-6

ISSN : 0007-9731

\section{Référence électronique}

Éric Palazzo, «Mariona vernet et Eulalia vernet (éd. et trad.), Ordo Virtutum: Hildegarda de Bingen », Cahiers de civilisation médiévale [En ligne], 252 | 2020, mis en ligne le 01 décembre 2020, consulté le 29 novembre 2022. URL : http://journals.openedition.org/ccm/5435; DOl : https://doi.org/10.4000/ccm. 5435

\section{(c) (i) (3)}

Creative Commons - Attribution - Pas d'Utilisation Commerciale - Pas de Modification 4.0 International - CC BY-NC-ND 4.0

https://creativecommons.org/licenses/by-nc-nd/4.0/ 
Ordo Virtutum: Hildegarda de Bingen, E. Vernet et M. Vernet (éd. et trad.), Barcelone, Universitat de Barcelona Edicions (Filologia UB), 2018.

Hildegarde de Bingen et son œuvre ne sont plus à présenter. Les médiévistes ont pris l'habitude de considérer les écrits de la théologienne visionnaire du XII $\mathrm{s}$. dont l'influence a été notoire pendant et après la période médiévale. On lui doit un grand nombre de traités et de textes théologico-mystiques où l'accent est principalement porté sur la dimension visionnaire de l'expérience spirituelle. Entrée très tôt au couvent de Disibodenberg, elle en devient l'abbesse en 1136. Par la suite, elle a fondé plusieurs monastères féminins. Son œuvre théologique, principalement axée sur la mystique et la dévotion, est considérable. Elle est également l'a. de textes relatifs à la médecine et au savoir scientifique. Le premier chapitre du livre d'Eulalia et Mariona Vernet est consacré à un panorama complet de la carrière et de l'œuvre de la mystique visionnaire qu'était Hildegarde de Bingen.

Le présent ouvrage contient une nouvelle édition du texte de l'Ordo Virtutum, ce «drame » musical composé par Hildegarde de Bingen vers 1151 à l'occasion de la reconstruction de l'abbaye de Rupertsberg. Il est possible que ce drame musical ait été joué à l'occasion de la consécration de l'église de Rupertsberg en 1152 ou bien pendant la fête de la consécration des vierges dans le même couvent. L'Ordo virtutum est donc un drame musical constitué de près de 80 poèmes musicaux de nature liturgique et organisés à partir de cinq parties. Ces poèmes mettent au prise l'âme humaine avec les vices et les vertus, autrement dit, la lutte du bien contre le mal. Tous les spécialistes s'accordent pour reconnaître dans cette œuvre une dimension à la fois théologique mais aussi et surtout morale qui convient bien dans le contexte monastique qui l'a vu naître.

Le présent livre a le mérite de proposer au lecteur une synthèse complète de nos connaissances actuelles sur l'Ordo Virtutum d'Hildegarde de Bingen dans des pages d'une grande précision et d'une parfaite clarté pour le lecteur non averti comme pour le spécialiste. Autrement dit, ce livre rendra de grand service à tous les médiévistes désireux de se pencher sur ce texte fondamental de la poésie musicale et liturgique du $\mathrm{XII}^{\mathrm{e}} \mathrm{s}$. Cette synthèse parfaitement menée par les deux auteurs transparaît aussi bien dans les chapitres introductifs à l'édition du texte et à sa traduction catalane que dans les observations tout à fait pertinentes sur le style littéraire d'Hildegarde, sur la musique et sa notation neumatique comme sur tout ce qui est dit de la codicologie des témoins manuscrits. Sur ce point, les deux auteurs semblent quelque peu critiques envers le travail immense réalisé jadis par le grand savant Peter Dronke au sujet de ce texte d'Hildegarde et auquel on doit l'édition qui fait toujours référence à ce jour. 
Mais, de mon point de vue, le grand mérite et l'apport essentiel de cette publication réside dans l'édition critique latine, de très grande qualité, et surtout dans la première traduction du texte latin en catalan. Les règles éditoriales de l'édition sont particulièrement soignées et il faut savoir gré aux auteurs d'avoir pris en compte la totalité des témoins manuscrits connus pour reconstituer le texte. Quant à la traduction catalane, elle marquera sans doute un tournant dans la diffusion de ces grands textes latins du Moyen Âge à travers les langues modernes et permettant de toucher un public plus large encore que les seuls spécialistes.

Éric PaLAzzo

UMR 7302 - CESCM

Université de Poitiers 